\title{
The salary cap proposal of the G-14 in European football
}

\author{
Dr. Stefan Kesenne, Professor of Economics \\ Economics Department, University of Antwerp (UA) \\ Physical Education Department, Catholic University of Leuven (KUL)
}

\author{
UFSIA, University of Antwerp \\ Prinsstraat, 13 \\ B-2000 Antwerp \\ Tel. 0032-3-2204105 \\ Fax. 0032-3-2204799 \\ E-mail: stefan.kesenne@ua.ac.be
}




\title{
The salary cap proposal of the G-14 in European football
}

\begin{abstract}
In this paper we try to show that a salary cap, as it is proposed by the G14, the association of the 18 most successful clubs in European football, is fundamentally different from the salary cap as it has been introduced in some major leagues in the U.S. Whatever the objectives, the impact of these two types of salary caps on the distribution of playing talent, which is the most important determinant of the competitive balance in a sports league, can be very different, depending, among other things, on the cost structure of the large and the small market clubs.
\end{abstract}




\section{The salary cap proposal of the $G-14$ in European football}

\section{Introduction}

It is well known that many professional football clubs in Europe are facing huge financial problems. Although some of the financial losses are aggravated by the recent bankruptcy of a few large pay television companies, many analysts agree that the main cause of these problems is the unreasonable rise in salaries club managers have granted their professional players after the 1995 Bosman verdict in the European Union. In the race for hiring and keeping the best players, the share of some clubs' payroll has risen to unsustainable percentages of the their total budget. Between 1995 and 2000, total wages and salaries have risen by an annual growth rate of $28 \%$ in England's Premier League, with a wage/turnover ratio of $60 \%$ in 2000, coming from only $47 \%$ in 1995. In England's Division One, the average wages/turnover ratio in 2000-2001 was $101 \%$. During the same period of 5 years, this ratio rose from $57 \%$ to $75 \%$ in Italy's top Series A, with some clubs, like Chievo, showing a ratio of $115 \%$. In the Netherlands the average top division wage/turnover ratio was $69 \%$ in 2000. Portugal saw its ratio increase from $71 \%$ to $95 \%$ in just 1 year. (see Deloitte and Touche, 2002).

In the free-agency player market that emerged after the abolition of the Reserve Clause in the mid seventies, the North American major leagues have experienced an 
explosion in player salaries (see Quirk and Fort, 1992). In the NBA (Basketball league) and the NFL (American football league), a salary cap has been imposed in order to limit the amount of money a club can spend on player salaries. Also in the $M L B$ (major league baseball) a luxury tax, which can be seen as a soft salary cap, tries to discourage salary increases.

Given the rise of player salaries after the Bosman verdict, and the poor financial situation of many football clubs, the G-14 (the organization of the 18 most successful football clubs in Europe) has recently proposed a different type of salary cap, given the different structure of European football. Whereas the main objectives of salary caps in the U.S. major leagues are to protect the owner profits and to guarantee a reasonable competitive balance, the G-14 salary cap seems to be all about financial prudence and controlling costs. Nevertheless, it is worthwhile to investigate how this proposal will affect the competitive balance in the European National football leagues, that are said to be very imbalanced with clubs playing in the same division having budgets that are up to 10 times the size of the budgets of other clubs. In 2000, Scotland's Rangers and Celtic both had a budget that was as high as the budget of the other 8 clubs together (see Deloitte and Touche, 2002). The same is true for the European Champions League where Manchester United has a budget that is 7 times the budget of, say, Belgian's Anderlecht (see KBC, 2000).

The objective of this paper is to find out how the G-14 type of salary cap, as distinct from the US salary cap, affects the competitive balance and the average player salary level. In section 2, a simple model is specified where both types of salary caps are compared in a profit maximizing league. Section 3 investigates the impact of the G-14 cap on the competitive balance in a win maximizing league. Section 4 concludes.

\section{The G-14 salary caps in a profit maximizing league}

Let's assume that a club's season revenue $R_{i}$ depends mainly on the size of the market $m_{i}$ and the number of units of playing talent $x_{i}$ (being the main determinant of the winning percentage), with the usual assumptions of a positive effect of the market size and a positive, but decreasing marginal effect of talent. 
$R_{i}=R\left(m_{i}, x_{i}\right) \quad$ with $\quad \frac{\partial R_{i}}{\partial m_{i}}>0 \quad \frac{\partial R_{i}}{\partial x_{i}}>0 \quad \frac{\partial^{2} R_{i}}{\partial x_{i}^{2}}<0$

The total $\operatorname{cost} C_{i}$ is the sum of the player cost and the capital cost, i.e.:

$C_{i}=c_{i} x_{i}+c_{i}^{0}$

where $c_{i}$ is the unit cost of playing talent and $c_{i}^{0}$ is the fixed (short term) capital cost . For simplicity reasons, the supply of talent is held constant. The unrestricted player market equilibrium is found where the marginal revenue of talent equals the marginal cost of talent: $M R_{i}=c$ for all $i$, where $c$ is the market clearing unit cost of talent.

A US salary cap, which is in fact a payroll cap, limits the total amount a club can spend on salaries, not the salary of an individual player. The cap is calculated as a percentage of defined gross revenue of the league, based on the total revenue of all clubs together, during the previous season, divided by the number of clubs in the league:

cap $=\frac{\alpha \sum_{i=1}^{n} R_{i,-1}^{*}}{n} \quad$ with $\alpha<1$

Both the gross revenue of the league $R^{*}$ and the percentage $\alpha$ is determined through collective bargaining between club owners and players associations. It follows that the amount of the cap is the same for all clubs. In fact, the US cap is also a floor, poorer teams must spend up to the cap, so that the cap, at least theoretically, should equate spending on talent. However, the latter implies that this regulation is no longer a cap as such, but rather a combination of a salary cap and a revenue sharing arrangement (see Quirk and Fort, 1992). It follows that a comparison between the impact of a US cap and a G-14 cap is more relevant if the US cap is considered as a pure payroll cap, without any revenue sharing between richer and poorer clubs, as in Kesenne (2000). 
The salary cap the G-14 has in mind deviates fundamentally from (3). The proposal is to fix a maximum wage/turnover ratio for each club or:

$\alpha R_{i}=$ cap $_{i} \quad$ with $\alpha<1 \quad$ so that: $\quad c t_{i} \leq \alpha R_{i}$

where $\alpha$ is the wage/turnover ratio. This cap is clearly different for each club and it is obvious that also the impact on the competitive balance and the salary level will be different.

In a profit maximizing league, a US salary cap in (3) will reduce the demand for playing talent of the large market clubs, as their demand curve becomes a hyperbolic function below their marginal revenue curve $(c=c a p / x)$. It is not unreasonable to assume that this cap does not affect the demand for talent of the small budget clubs. It follows that a more equal distribution of talent between large and small market clubs emerges with also a lower average player salary level (see Kesenne, 2000). This can be illustrated in Figure 1 for a simple 2-club model, where we assume that $R^{*}=R$ for simplicity reasons.

\section{Figure 1. US salary cap}

On the horizontal axis, the clubs' units of talent are measured, from left to right for the large market club, and from right to left for the small market club. The distance between the two origins is the total supply of talent. On the vertical axis, the salary level is indicated. The point of intersection between the two marginal revenue curves, which are the demand curves for talent under profit maximization, is the unrestricted market equilibrium A. The salary cap is represented by the hyperbolic curve CAP, which is now the demand curve for the large market club. The new market equilibrium is found in point B. The salary cap improves the distribution of talent between the large and the small market club and lowers the average salary level.

The G-14 salary cap in (4) comes close to a macroeconomic proposal of Weitzman (1984) to fight stagflation, which he called the 'share economy'. An implication of 
this labour compensation system is that the marginal revenue of a playing talent (MR) is always higher than the marginal cost (MC):

$M C_{i}=\frac{\partial\left(c_{i} x_{i}+c_{i}^{0}\right)}{\partial x_{i}}=\frac{\partial\left(\alpha R_{i}+c_{i}^{0}\right)}{d x_{i}}=\alpha \frac{\partial R_{i}}{\partial x_{i}}=\alpha M R_{i}$

It follows that profit maximizing clubs are willing to hire talent until the marginal revenue is zero. It is likely that this will cause an excess demand on the market of playing talent. If we assume that players are choosing the best paying club, it can be shown that this type of salary cap can worsen the competitive balance.

The compensation per unit of playing talent by each club is given by:

$c_{i}=\frac{\alpha R_{i}}{x_{i}}=\alpha A R_{i}$

If the salary cap is binding for all clubs, large and small, the market equilibrium is found where:

$\alpha A R_{i}=c \quad$ or $\quad A R_{i}=c / \alpha \quad$ for all $i$

where $c$ is the equilibrium marginal cost of talent. The market equilibrium is now found at the point of intersection of the AR-curves. It follows that imposing the G-14 cap results in the same market equilibrium as in a winning maximizing league, at least in the absence of any capital cost (see Kesenne, 1996).

Compared with the unrestricted market equilibrium in a profit maximizing league, the G-14 salary cap can cause a more unequal distribution of talent. An example for a simple 2-club league can show this. Assuming a quadratic revenue function for the large and the small market club:

$R_{i}=m_{i} x_{i}-b x_{i}^{2} \quad$ for $i=1,2 \quad$ and $\quad m_{1}>m_{2}$

and a constant supply of talent, that is put equal to unity, it can be calculated that the large market club hires more talent if a salary cap is imposed. 
$x_{1}=0.5+\frac{m_{1}-m_{2}}{2 b}>0.5+\frac{m_{1}-m_{2}}{4 b}$

This can also be illustrated in figure 2, where both the marginal and the average revenue curves are drawn for quadratic revenue functions.

\section{Figure 2. G-14 salary cap in a profit maximizing league}

The point of intersection (D) of the AR-curves shows a more unequal distribution of playing talent than the point of intersection (A) of the MR-curves. However, the salary level that emerges after the introduction of the salary cap, is not fixed at the point of intersection of the AR-curves, because it depends on the share parameter. If the main objective of the G-14 type of salary cap is to lower the player salaries, the share parameter will be chosen low enough in order to lower the player compensation (the G-14 is considering $60 \%$ ). The player salary can then simply be calculated as:

$c=\frac{\alpha R_{i}}{x_{i}}=\alpha\left(m_{1}-b x_{1}\right)$

However, a few remarks are in place at this point.

Firstly, the above result is derived for a simple quadratic revenue function. Fort and Quirk (2000) have shown that nothing can be derived regarding the competitive balance in a win maximizing league compared with a profit maximizing league if no simplifying assumptions beyond concavity are made for the revenue function. For example, it can be easily shown that for a Cobb-Douglas revenue function the distribution of playing talent is the same in a profit and a win maximizing league (see Dobson and Goddard, 2001). It is clear that also for a quadratic revenue function, the competitive balance can be more equal in a win maximizing league if the parameter $b$ in (8) is different for each club, and much higher for the large market club than for the small market club. But in that particular case, the distribution of talent is such 
that the small market club has the highest number of talents (see Kesenne, 2002), which is not really a situation most leagues care about.

Secondly, it is possible that the G-14 salary cap is not binding for all clubs. In the quadratic revenue example above, the small club has a larger wage/turnover ratio than the large market club $\left(c x_{1} / R_{1}=4 c /\left(3 m_{1}+m_{2}-2 b\right)>c x_{2} / R_{2}=4 c /\left(3 m_{2}+m_{1}-2 b\right)\right.$. In case the chosen value of $\alpha$ is such that it does not affect the large market club, but reduces the payroll of the small market club, the result is also a more unbalanced distribution of playing talent, as can be shown for the quadratic revenue function. It follows than one can safely conclude that the G-14 salary cap worsens the competitive balance in a profit maximizing league.

\section{The G-14 salary cap in a win maximizing league}

Many economists have serious doubts that European football clubs are profit maximizers (see Sloane, 1971). They prefer to think of clubs as win maximizers, which means that clubs are rather maximizing their sportive succes, taking account of the size of their budget. This does not exclude that these clubs can be profitable. Given a fixed profit rate, clubs can still aim to maximize their winning percentage. What is the impact of the G-14 type of salary cap in this scenario?

If we assume that clubs are maximizing talent, which is the only way a club can maximize the winning percentage, under the following budget constraint:

$$
c_{i} x_{i}+c_{i}^{0}=R_{i}
$$

where $c_{i}^{0}$ can also include a certain profit level, it can be derived that the clubs' demand for talent is given by the net average revenue curve:

$$
A R_{i}^{N}=\frac{R_{i}-c_{i}^{0}}{x_{i}}
$$

The market equilibrium is then found where:

$$
A R_{i}^{N}=c \quad \text { for all } i
$$


If the G-14 salary cap (4) is imposed, the market equilibrium is again given by (7) so that we can compare both equilibria. In this case, different outcomes are possible depending on the size of the fixed capital cost. If the capital cost is assumed to be proportional to the talents of a club with proportionality factor $\varepsilon$ :

$c_{i}^{0}=\varepsilon x_{i} \quad$ so that $\quad A R_{i}=A R_{i}^{N}+\varepsilon$

the distribution of talents will be the same as before. For obvious reasons, the average salary level, depending on the value of the share parameter, will again be lower.

Figure 3. The G-14 salary cap

However, a few figures from the Premier League indicate that $\varepsilon$ is, on average, smaller for the small clubs than for the big clubs. Assuming that the large clubs are also the better performing clubs, the wage/turnover ratio also indicates the size of $\varepsilon$. The higher the wage/turnover ratio, the lower the value of $\varepsilon$. In table 1 the wage/turnover ratio's are given for the top 5 clubs and the bottom 5 clubs during the 2000-2001 season. The average ratio for the strongest clubs is 57\% and $68 \%$ for the weakest clubs.

Table 1 Wage/turnover ratio's (2000-2001)

\begin{tabular}{llll} 
1. Man United & $56 \%$ & 16. Everton & $80 \%$ \\
2. Arsenal & $65 \%$ & 17. Derby & $76 \%$ \\
3. Liverpool & $59 \%$ & 18. Man City & $38 \%$ \\
4. Leeds & $50 \%$ & 19. Coventry & $81 \%$ \\
5. Ipswich & $56 \%$ & 20. Bradford & $63 \%$ \\
\hline
\end{tabular}

Deloitte and Touche, 2002 
If $\varepsilon$ is indeed smaller for the small clubs, the G-14 type of salary cap will worsen the competitive balance in a win maximizing league. This can be seen by considering the shifts of the demand curves of the large and small market club in figure 3. In a win maximizing league, the net average revenue curves are the demand curves for talent. If the unrestricted market equilibrium is given by point E, after the introduction of the salary cap, the equilibrium is point $D$, because the distance between the AR-curve and $A R^{N}$ is larger for the large club than for the small club, according to (14). It follows that the G-14 salary cap will also worsen the competitive balance in a win maximizing league.

Of course, one of the concerns of the G-14 is the reduction of the huge financial losses many European football clubs are facing, and the huge debt they ran into. It follows the point of reference, in analysing the impact of a salary cap, should not be the breakeven situation for all clubs, such as point E in figure 3. But if the financial losses of the small market clubs are larger than those of the large clubs (see Deloitte and Touche, 2002), it is obvious that also in that case the G-14 salary cap will worsen the competitive balance.

\section{Conclusion}

In this contribution we have shown that the salary cap, that it has been proposed by the G-14 in European football, for reasons of financial prudence, can be expected to have a negative impact on the distribution of talent among clubs and on the competitive balance in a league. In a win maximizing league, which seems to be the case in most European national football leagues, one of the crucial factors turns out to be the cost structure of the small and large market clubs. 


\section{References}

- Deloitte and Touche, (2002), Annual Review of Football Finance, Manchester, $66 \mathrm{p}$.

- Dobson S., Goddard J., (2001), The Economics of Football, Cambridge U.P., Cambridge, $458 \mathrm{p}$.

- Fort R.D., Quirk J., (2000), Sports Team Behavior and Sports Policy: the winning percent maximizing league, discussion paper, Economics Department, Washington State Univ., Pulllman, 31 p.

- KBC, (2000), Football and Economics, Economic \& Financial Bulletin, 55/6, pp.1-16

- Kesenne S. (1996), League Management in Professional Team Sports with Win Maximizing clubs, European Journal for Sport Management, 2/2, pp 14-22

- Késenne S., (2000), The Impact of Salary Caps in Professional Team Sports, Scottish Journal of Political Economy, vol.47, nr.4, pp. 422-430

- Kesenne S., (2002), Competitive Balance and Revenue Sharing when rich clubs have poor teams, mimeo, Economics Department, Univ. of Antwerp, 12 p.

- Quirk J., Fort R.D., (1992), Pay Dirt, the business of professional team sports, Princeton Univ. Press, 535 p.

- Sloane P., (1971), The Economics of Professional Football: The Football club as a Utility Maximizer, Scottish Journal of Political Economy, vol.17/2, pp. 121-146

- Weitzman M., (1984), The Share Economy, Harvard University Press, Cambridge, Mass., 167 p. 


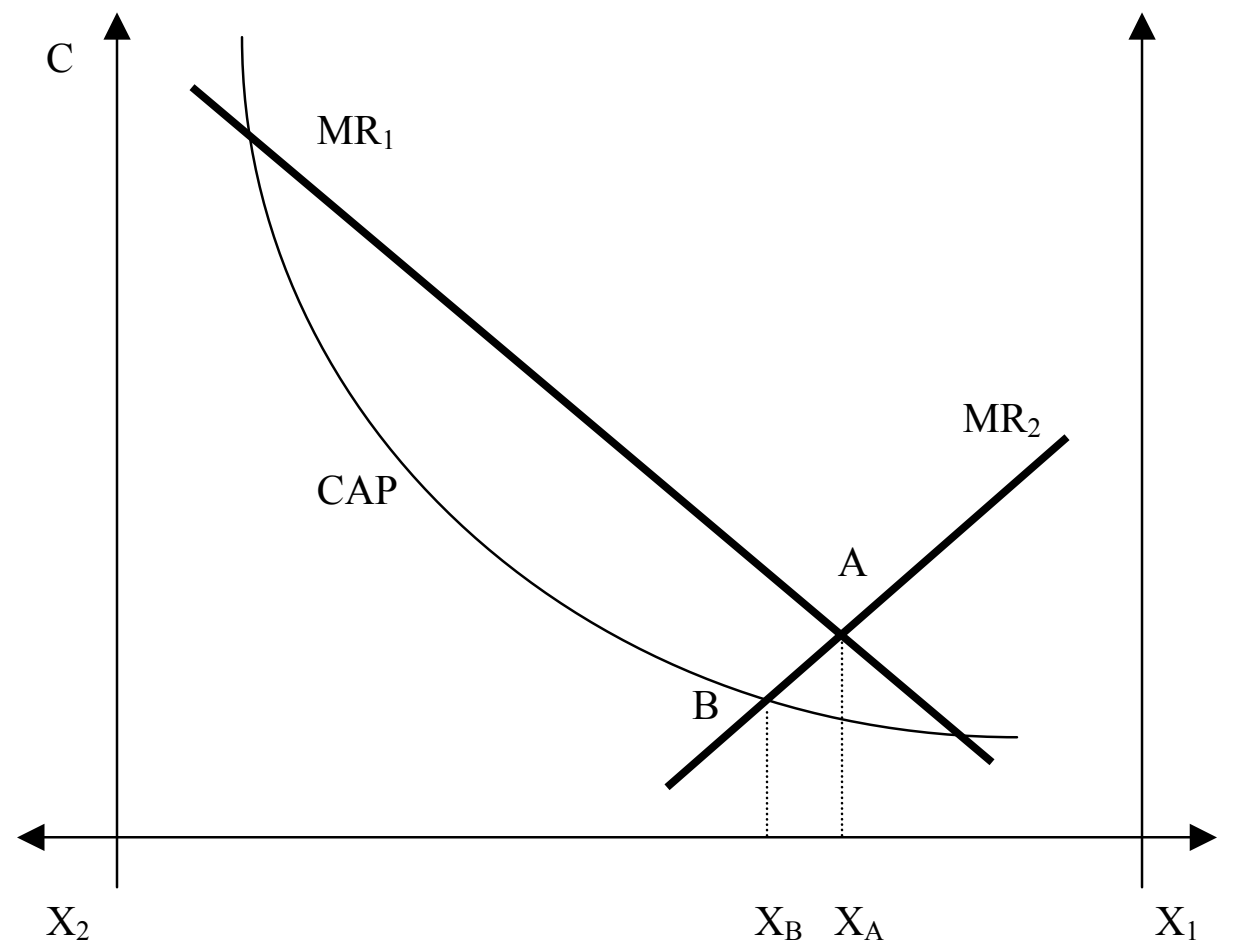

Figure 1 


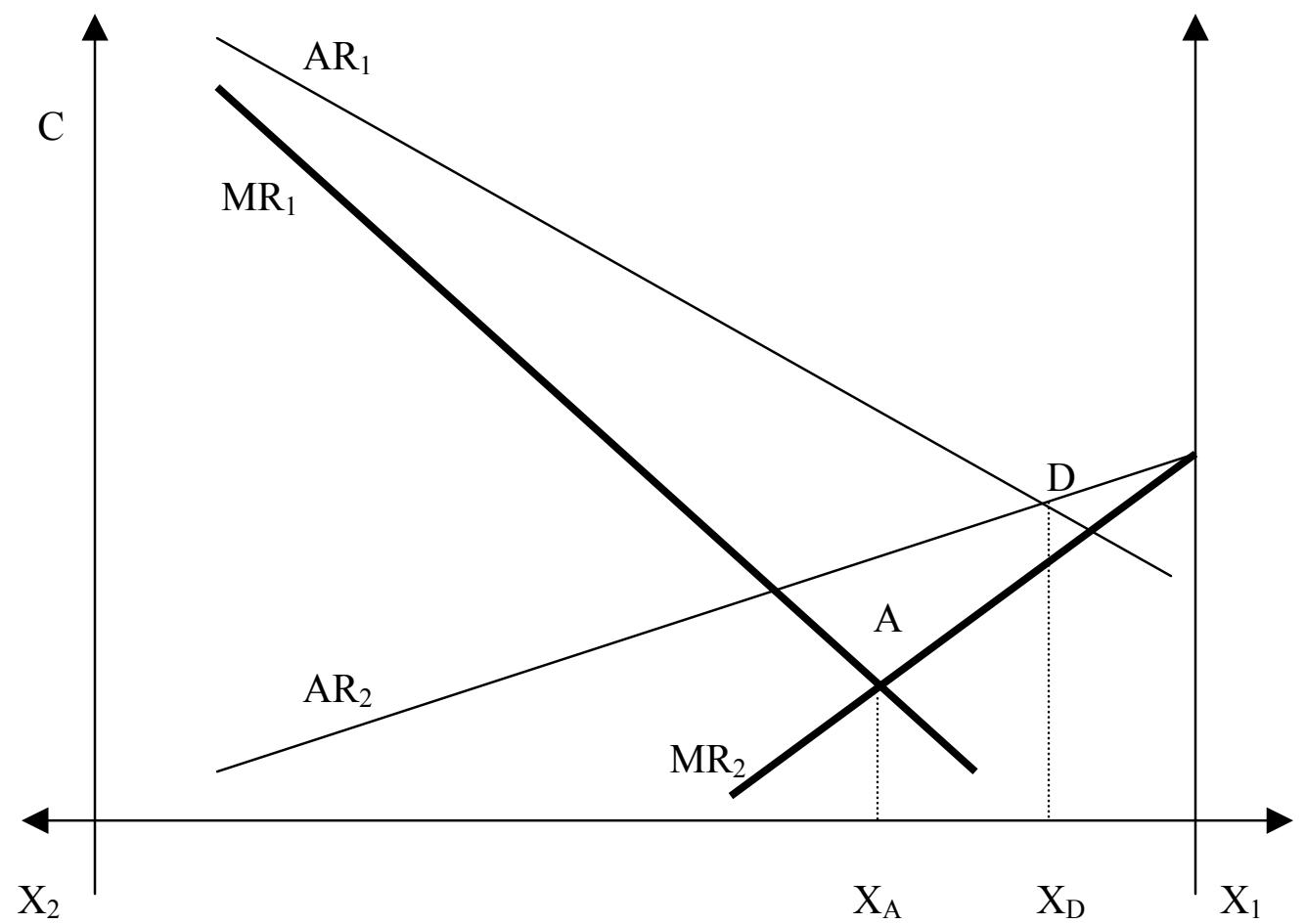

Figure 2 


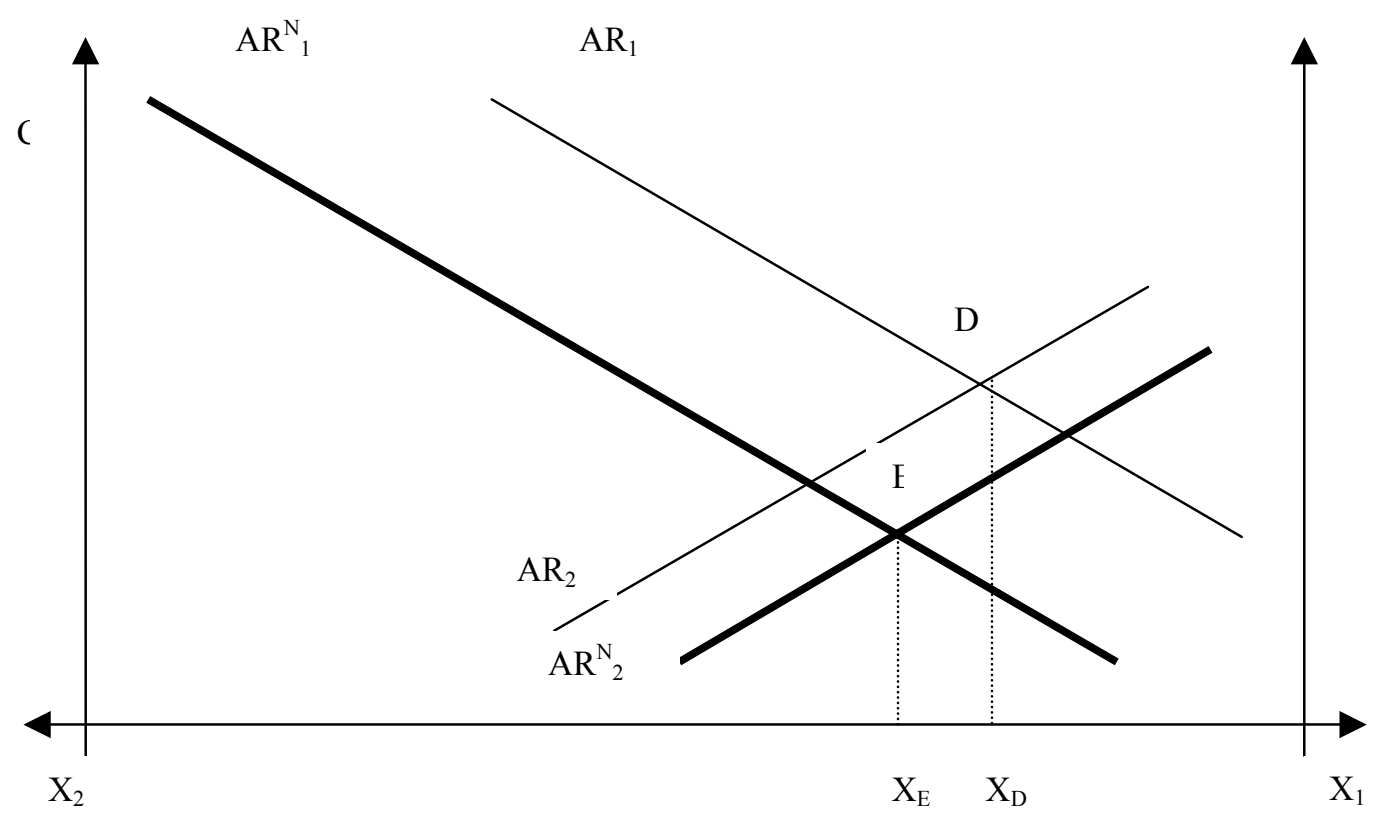

Figure 3 